\title{
Wolff-Parkinson-White syndrome: Implications for an anaesthesiologist
}

\author{
Vinaya Udaybhaskar, C. Sreemayee, Prasad Ingley ${ }^{1}$
}

\begin{abstract}
Wolff-Parkinson-White (WPW) syndrome is an electrical conduction abnormality of the heart that can induce potentially fatal arrhythmias at intermittent intervals. The induction and maintenance of general anaesthesia for a patient with WPW syndrome are risky due to the triggering capability of arrhythmias by various drugs and instrumentation. We hereby present the case of a 28-year-old male with previous cardiac illness, admitted for neurosurgical procedure, with drug-controlledWPW syndrome. The pre-operative optimisation, intraoperative scrutiny and vigil, along with readiness of standby medications and defibrillator made the ingress and egress from general anaesthesia uneventful. Thus, the potential dangers ofWPW syndrome can be circumvented with watchful preparedness and meticulous monitoring.
\end{abstract}

Key words: Arrhythmia, neuroanaesthesia,Wolff-Parkinson-White syndrome

\section{INTRODUCTION}

Wolff-Parkinson-White (WPW) syndrome also known as pre-excitation syndrome, is an electrophysiological disorder of the heart, prevalent in about $0.9 \%-3 \%$ of the general population. ${ }^{[1]}$ It is characterised by cardiac dysrhythmias, such as long or short QT syndromes, short PR interval, delta wave, ST depression and atrial fibrillation. ${ }^{[1,2]}$ Asymptomatic patients with the above electrocardiograph (ECG) and heart rhythm abnormalities are said to have WPW pattern. ${ }^{[3]}$ Patients complaining of palpitation, dizziness or dyspnoea along with this, have what is popularly known as the classical WPW syndrome. ${ }^{[2]}$ WPW syndrome is bothersome to the anaesthesiologist, as some anaesthetic drugs tend to alter the physiology of the atrioventricular (AV) conduction, and trigger arrhythmias. ${ }^{[4,5]}$ Moreover, procedures such

Departments of Anaesthesiology and ${ }^{1}$ Neuroanaesthesiology, JNMC and AVBRH, Wardha, Maharashtra, India

Address for correspondence:

Dr. Prasad Ingley, Department of Neuroanaesthesiology, JNMC and AVBRH, Sawangi (Meghe), Wardha - 442 001, Maharashtra, India.

E-mail: drprasadingley@gmail.com

\begin{tabular}{|l|l|}
\hline \multicolumn{2}{|c|}{ Access this article online } \\
\hline Quick Response Code: & Website: \\
\hline & www.jnaccjournal.org \\
\hline & \\
\hline
\end{tabular}

as laryngoscopy, intubation and extubation can trigger a sympathetic drive, that can be arrhythmogenic in patients with WPW syndrome. ${ }^{[3,6,7]}$ Therefore, the anaesthetic management of these patients should be customized according to the surgical procedure and the presenting condition of the patient. We hereby present the following case report of management of a patient with the previous history of ventricular septal defect (VSD) repair with aortic valve replacement (AVR) and WPW syndrome that was posted for a neurosurgical procedure.

\section{CASE REPORT}

A 28-year-old male, with a significant past medical history of VSD repair and AVR in 2003, was a diagnosed case of WPW syndrome since 2012. He had required multiple hospital and Intensive Care Unit admissions for the management of WPW syndrome, almost once every alternate month since past 1 year, receiving treatment with intravenous (IV) adenosine and two synchronised cardioversion shocks [Figures 1 and 2] He was finally on warfarin and beta-blockers, and taught

This is an open access article distributed under the terms of the Creative Commons Attribution-NonCommercial-ShareAlike 3.0 License, which allows others to remix, tweak, and build upon the work non-commercially, as long as the author is credited and the new creations are licensed under the identical terms.

For reprints contact: reprints@medknow.com

How to cite this article: Udaybhaskar V, Sreemayee C, Ingley P. Wolff-Parkinson-White syndrome: Implications for an anaesthesiologist. J Neuroanaesthesiol Crit Care 2017;4:49-52. 
carotid massage as a life-saving bedside first aid. The patient now presented with complaints of incessant vomiting and headache. He was subsequently diagnosed to have a right temporoparietal glioma on magnetic resonance imaging, and thus planned for early operative intervention.

On admission and pre-operative work up, international normalised ratio (INR) was three. Warfarin was hence stopped and converted to low molecular weight heparin - injection enoxaparin $40 \mathrm{mg}$ OD. His INR was brought down to 1.03 on the day of surgery. Two-dimensional (2D) echo was done to assess the ventricular function and rule out any akinesia, hypokinesia or atrial clots on admission and the day of surgery.

A staged induction was planned. Standard AANA monitors were applied. The patient was covered by an inline warming blanket. Premedication was done with midazolam $2 \mathrm{mg}$ (IV) and fentanyl $50 \mathrm{mcg}$ IV, and he was pre-oxygenated with $100 \%$ oxygen through facemask. Antiarrhythmic drugs including adenosine, esmolol, lidocaine, amiodarone and defibrillator were kept on standby [Figure 3]. Following pre-oxygenation, IV lidocaine $60 \mathrm{mg}$ and propofol $100 \mathrm{mg}$ in titrated dose, were administered for

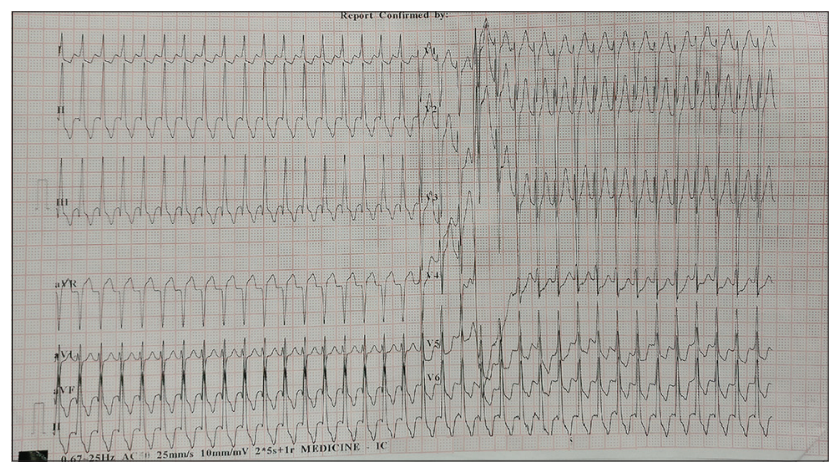

Figure 1: Electrocardiograph showing Wolf Parkinson White pattern during acute episode

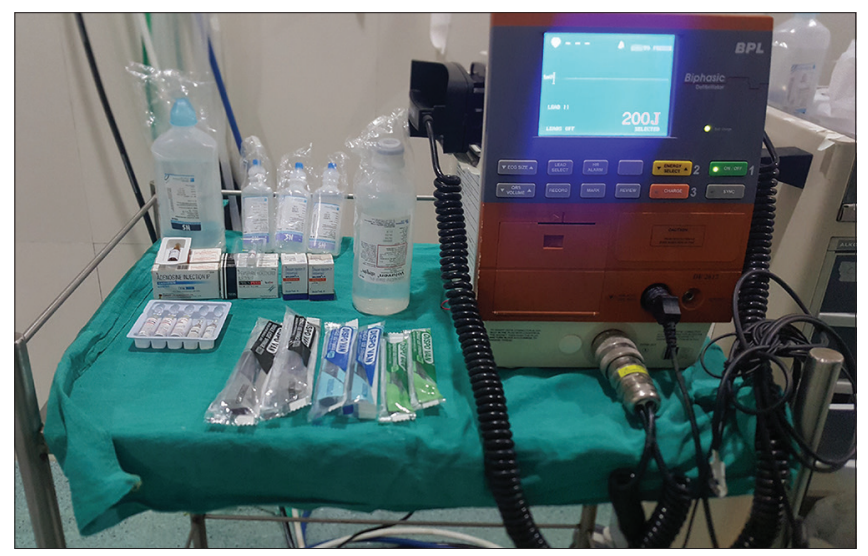

Figure 3: Preparedness for event with drugs and defibrillator induction of anaesthesia. Muscle relaxation was achieved by injection vecuronium, priming was done followed by loading dose. Laryngoscopy was done smoothly with no cardiopressor response and intubated with flexometallic tube $8.0 \mathrm{~mm}$. Oral endotracheal tube was confirmed by the presence of bilateral breath sounds, and end-tidal $\mathrm{CO}_{2}$ on capnography.

General anaesthesia was maintained with IV propofol infusion at the rate of $3 \mathrm{mcg} / \mathrm{kg} / \mathrm{min}$ and the delivery of $0.8 \%$ expired sevoflurane in combination with oxygen $1 \mathrm{~L} / \mathrm{min}$ and air $2 \mathrm{~L} / \mathrm{min}$. Fentanyl was administered in $50 \mathrm{mcg}$ at hourly intervals. Lead II was used for intraoperative ECG monitoring [Figure 4] which sustained the expected findings of a shortened PR interval, delta wave and widened QRS as seen on the pre-operative 12-lead ECG. Neuromuscular blockade was antagonized with the administration of IV glycopyrrolate $0.1 \mathrm{mg}$ and IV neostigmine $2.5 \mathrm{mg}$ in titrated dose. He was also given IV metoprolol $5 \mathrm{mg}$, IV esmolol $10 \mathrm{mg}$ and IV lignocaine $60 \mathrm{mg}$ in titrated dose according to the heart rate. An uneventful extubation was performed, and the patient had a smooth emergence. Post-extubation nebulisation was given. An agreeable

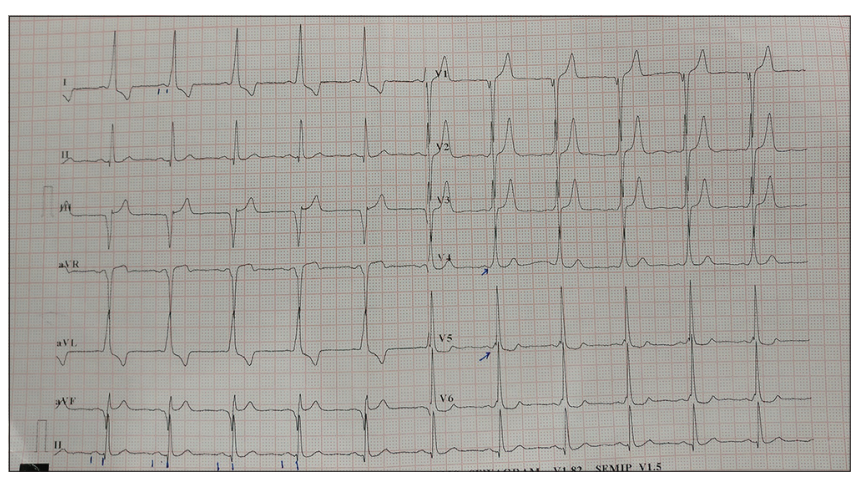

Figure 2: Post-adenosine reversibility of Wolf-Parkinson-White pattern

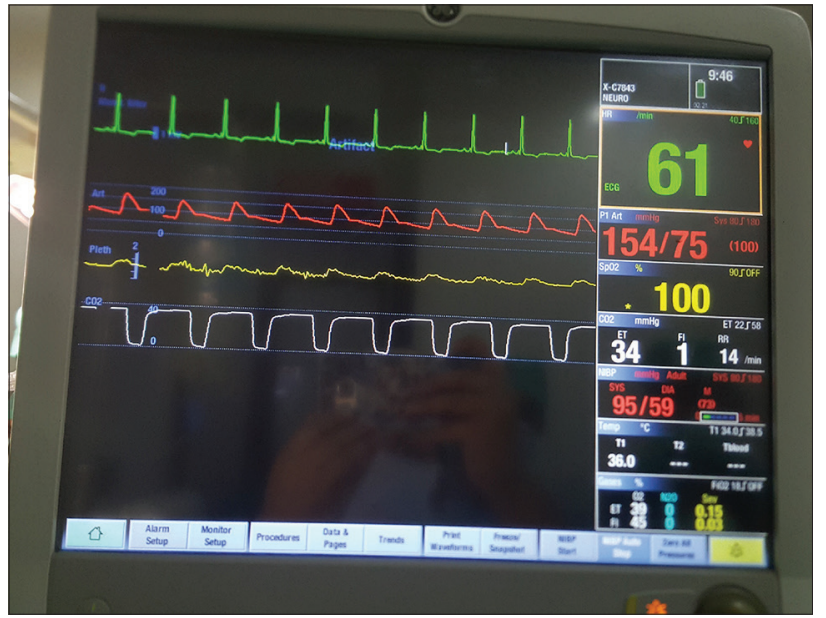

Figure 4: Intraoperative monitoring showing normal electrocardiograph pattern and vital parameters 
post-operative recovery without any adverse events or anaesthetic complications ensued.

In post-anaesthesia recovery, he was given adequate analgesics and was comfortable, alert and oriented. Vital signs included a pulse rate of 80 beats/min, blood pressure of $110 / 74 \mathrm{mmHg}$, respiratory rate of 12 breaths/min, and $100 \% \mathrm{SpO}_{2}$. A post-operative $2 \mathrm{D}$ echo was done to assess any aortic valve for any clots or vegetations. Enoxaparin was restarted a day after the surgery and the patient warfarinised 2 days later.

\section{DISCUSSION}

The pathophysiology behind WPW syndrome lies in an aberrant re-entrant electrical pathway in the conducting system of the heart, which is responsible for all the rhythm changes. WPW syndrome can be categorised into three types: Orthodromic AV re-entrant tachycardia, antidromic AV re-entrant tachycardia and Atrial fibrillations or flutter. ${ }^{[2]}$

Several drugs routinely used in anaesthetic practice are potentially arrhythmogenic in patients with WPW syndrome. These include antimuscarinic agents, like atropine and glycopyrrolate, vagolytics, such as pancuronium, histamine releasing agents, like atracurium, and sympathomimetic agents (ketamine), particularly beta-1 agonists. ${ }^{[4]}$ These can hence be a bane in patients with WPW syndrome and should be ideally avoided. Sevoflurane and isoflurane, however, have no stimulatory influence on the conduction through accessory pathway, and thus the former is preferred as volatile agent of choice in WPW syndrome. Moreover, sevoflurane has also been found to suppress the accessory pathway conduction and prolong refractory period of the heart. ${ }^{[2,8]}$

Other drugs that are either neutral or beneficial against the aberrant pathway conduction in WPW syndrome, and can be safely used include - propofol, fentanyl, rocuronium, mivacurium, cisatracurium, benzodiazepines, thiopental and nitrous oxide. On the other hand, drugs that can instigate cardiac arrythmias and should be avoided include halothane, digitalis, verapamil, neostigmine and oxytocin. Of these, digitalis and verapamil can accelerate the ventricular response in atrial fibrillation and flutter to dangerous levels, because they suppress AV nodal conduction, and thus favour preferential conduction through the aberrant pathway. ${ }^{[2]}$

In our case, neurosurgery mandated general anaesthesia and endotracheal intubation. Smooth intubation without triggering any pressor response was achieved and the premedication and induction drugs were titrated so as to have its peak effect during intubation. Hypothermia and hypotension as triggering factors were avoided. The risks and benefits of reversing neuromuscular blockade were weighed judiciously. A slightly lower dose of glycopyrrolate $0.1 \mathrm{mg}$ with neostigmine $2.5 \mathrm{mg}$ was given, which had no significant effect on heart rate but caused sufficient reversal of neuromuscular blockade. Till today, until a better drug is available, glycopyrrolate is still preferred over atropine as the antimuscarinic agent of choice.

Patients who are haemodynamically stable and asymptomatic usually do not require any treatment preoperatively. However, meticulous planning and preparedness can be the game changer for patients with WPW syndrome. Drugs such as adenosine, phenylephrine, beta-blockers and antiarrhythmic agents should be available and ready. A defibrillator should also be on standby ${ }^{[9]}$ If an arrhythmia is triggered and results in haemodynamic instability, direct synchronised cardioversion is indicated. In the haemodynamically stable patients, Class 1 antiarrhythmics (disopyramide, lidocaine and procainamide) and calcium channel blocker (diltiazem) can be used to interrupt re-entrant tachycardias. ${ }^{[2,8]}$

\section{CONCLUSION}

WPW syndrome, although rare, is a dangerous situation to encounter for the anaesthesiologist preparing for general anaesthesia. One must be aware of the potential dangers involved and absolutely clear regarding the prophylactic measures and emergent treatments that may be required during the intraoperative management. It is thus imperative to be able to anticipate possible detrimental outcomes that may occur, and take appropriate measures to circumvent a probable catastrophe in the operating room.

\section{Financial support and sponsorship} Nil.

\section{Conflicts of interest}

There are no conflicts of interest.

\section{REFERENCES}

1. Morgan E, Mikhail M, Murray M. Clinical Anesthesiology. $4^{\text {th }}$ ed. New York: Lange Medical Books, McGraw Hill Medical Pub. Division; 2006. p. 435-9.

2. Bengali R, Wellens HJ, Jiang Y. Perioperative management of the Wolff-Parkinson-White syndrome. J Cardiothorac Vasc Anesth 2014;28:1375-86.

3. Sahu S, Karna ST, Karna A, Lata I, Kapoor D. Anaesthetic management of Wolff-Parkinson-White syndrome for hysterectomy. Indian J Anaesth 2011;55:378-80.

4. Stoelting RK, Hines RL, Marschall KE. Abnormalities of cardiac conduction and cardiac rhythm. Stoelting's Anaesthesia and Co-existing Disease. Saunders, Elsevier; 2012.

5. Schoenstadt DA, Whitcher CE. Observations on the mechanism of succinyldicholine-induced cardiac arrhythmias. Anesthesiology 1963;24:358-62. 
6. Kuner J, Enescu V, Utsu F, Boszormenyi E, Bernstein $\mathrm{H}$, Corday E. Cardiac arrhythmias during anesthesia. Chest 1967;52:580-7.

7. Lubarsky D, Kaufman B, Turndorf H. Anesthesia unmasking benign Wolff-Parkinson-White syndrome. Anesth Analg 1989;68:172-4.
8. Gupta A, Sharma J, Banerjee N, Sood R. Anesthetic management in a patient with Wolff-Parkinson-White syndrome for laparoscopic cholecystectomy. Anesth Essays Res 2013;7:270-2.

9. Namshikar V, Bharne S. Anesthesia for Wolff-Parkinson-White syndrome: A report of two cases. Saudi J Anaesth 2013;7:354-6. 